\title{
Should hormone replacement therapy be used in postmenopausal women for voiding dysfunction?
}

\section{Lynn Stothers, MD, MPH, FRCSC}

The purpose of the Point / Counterpoint section is to encourage vigorous and informed discussion on controversial issues in urology through the presentation of diverse opinions. We aim for a dispassionate discussion of controversies, recognizing that strong passions may exist in support of some positions.
$\Lambda$ rguably there are 2 significant questions when considering instituting a new therapy for a patient: Does the therapy work for the condition present? and, Do the benefits outweigh the risks?

For decades, estrogens have been used successfully in the treatment of lower urinary tract disorders such as voiding dysfunction and infections, and, to a lesser extent, incontinence. However, concerns about increased risk of heart disease, breast cancer, blood clots and stroke have decreased physicians' enthusiasm for prescribing hormone replacement therapy (HRT). Nevertheless, there is significant indication that the particular formulation, route of administration, timing and duration of treatment are important variables in the risk, type, prevalence and severity of adverse effects. ${ }^{1}$ If these considerations are taken into account, estrogens, in some form, will likely continue to play a role in the management of voiding dysfunction.

Estrogens first became popular for the treatment of lower urinary tract symptoms following the discovery of estrogen receptors in the urogenital tract and demonstration that estrogen reversed some or all of the tissue atrophy associated with menopause. Short durations (3-6 mo) of HRT (estrogen or estrogen plus progesterone) have been shown to have a positive effect on periurethral vessels. ${ }^{2}$ Both subjective reports and randomized controlled trials have found significant benefits from the use of estrogen for urinary tract problems, particularly infections, overactive bladder symptoms and, to a lesser extent, incontinence.
Urinary tract infection, although not normally included in the definition of voiding dysfunction, is a common and bothersome problem for postmenopausal women. It is likely that lowered estrogen levels are at least a contributing factor in the development of urinary tract infections. A recent Cochrane systematic review ${ }^{3}$ found that treatment with vaginal estrogens reduced the number of urinary tract infections in postmenopausal women with recurrent infections, and in fact may be more effective than antibiotics. Results varied with the type of estrogen used and the treatment duration. Based on current findings, further research on the efficacy of local estrogen in the prevention of urinary tract infections in postmenopausal women is warranted.

Studies on the effect of HRT on incontinence have had inconsistent results. Early uncontrolled studies found benefit, ${ }^{4}$ but subsequent randomized controlled trials found little or no benefit, and some even reported negative effects with systemic estrogens. ${ }^{5-8}$ A 2003 Cochrane systematic review ${ }^{9}$ reported on the effectiveness of estrogens related to incontinence. The review found 28 randomized or quasirandomized controlled trials that used a variety of combinations of estrogen and had varying treatment durations. Fifteen of these trials had a placebo arm as part of the study design. The review found that systemic estrogen treatment, with the specific formulation not defined, could improve or cure incontinence, particularly urge incontinence, in about $50 \%$ of patients, compared with about $25 \%$ with placebo. $^{9}$ 
Subsequent to the Cochrane review, 2 large studies were completed that have been the subject of many papers. The Women's Health Initiative trial, ${ }^{10}$ which had both observational and randomized components, and the Heart Estrogen/progestin Replacement Study (HERS) ${ }^{11}$ were both designed to assess cardiovascular risk with HRT. Both found increases in incontinence among women taking systemic equine estrogen, with or without progestin. However, these reports were analyses of selfreports, and urinary symptoms were not primary outcome measures of either study. In addition no other types, routes, or dosages of estrogen were evaluated, and in these reports, other variables that may be important confounders, such as body mass index, tobacco use and caffeine use were not controlled in the analyses. The interpretations of both of these studies continue to evolve. ${ }^{12}$

Another possible use of estrogen related to incontinence is that, used preoperatively, estrogen has been found to improve outcomes of incontinence repair procedures. ${ }^{13}$

Hormone replacement therapy is highly successful in the management of peri- and postmenopausal symptoms, and in the prevention of osteoporosis and nonosteoporotic fractures. ${ }^{14} \mathrm{Non}$ oral regimens have been shown to maintain and even increase bone mineral density among users, even for estrogen doses that are considered to be too low to have a beneficial impact on other menopausal symptoms. ${ }^{14}$ Hormone replacement therapy may also have a protective effect against colorectal cancer and lung cancer. ${ }^{12,15}$

Concerns about the effects of estrogen related to cardiovascular disease were raised when the Women's Health Initiative found adverse effects on cardiovascular health, particularly for prolonged and late-initiated oral administration of estrogen, and particularly in combination with progestins. ${ }^{16}$ However, further analyses of this study, controlling for potential confounders, have shown that there is little if any additional risk associated with HRT, and that the risks are likely not higher than with other commonly prescribed medication. ${ }^{12}$ The large randomized controlled trial HERS did not find any increased risk of cardiovascular incidents among women with existing coronary artery disease. Transdermal HRT may actually reduce cardiovascular risk among smokers ${ }^{17}$ and obese patients. ${ }^{18}$

Other randomized controlled trials have confirmed the results of observational studies indicat- ing the safety and benefit of HRT in young (age $<60 \mathrm{yr})$ recently menopausal women $(<10 \mathrm{yr}$ since menopause). ${ }^{1,19}$ Significant cardiovascular and oncological adverse effects have not been associated with local administration in treatments such as vaginal creams, vaginal rings and transdermal patches.

Hormone therapy has been shown to somewhat increase the risk of stroke, but in younger women, with lower stroke risk, the risk of stroke attributable to HRT is quite low and might be further reduced by the use of lower doses, shorter treatment durations or both, ${ }^{20}$ or administration routes other than oral.

Studies have also found increased risks for breast cancer and stroke (relative risk 1.4, 95\% confidence interval 1.1-1.8), ${ }^{21}$ but there has been no clear demonstration of increase or decrease in risk of breast cancer in those women who begin HRT soon after menopause. ${ }^{11}$ Progesterone is used along with estrogen in women who still have their uterus. In these women, if estrogen is taken without progesterone, it increases the risk of cancer of the endometrium. Further assessments for the risks of stroke, cancer and thrombosis are still under investigation.

Both vaginal preparations ${ }^{22}$ and transdermal $\mathrm{HRT}^{23}$ have been shown to be as effective as oral therapy with respect to vascular changes. Transdermal estrogen may be more effective than the oral form with respect to modifying vascular symptoms of menopause, including incontinence, and may be safer with respect to thrombotic risk, ${ }^{24}$ and specific estrogen receptor modulators may increase the vascular benefits while reducing the risk of breast cancer. ${ }^{25}$

Newer formulations of HRT for urological problems may include growth hormones, ${ }^{26}$ herbal supplements, ${ }^{27} \alpha$-adrenergic agonists, ${ }^{28}$ lower dosages of estrogen, ${ }^{25}$ natural estrogens and phytoestrogens. ${ }^{29}$

More research is required to investigate differences in risk across the wide variety of hormone regimens, especially the different types of progestogens, ${ }^{24}$ and to assess newer combination formulations.

Ultimately, it is the patient's decision to take the risk of estrogen along with the benefits. Counselling, treatment schemes (e.g., short-term use and local administration) and identification of specific symptoms being targeted will help both patient and physician in reaching a satisfactory decision. 
Associate Professor of Urology, Associate Member, Department of Health Care and Epidemiology, Associate Member, Department of Pharmacology, and Head of Research, UBC Bladder Care Centre, Department of Urology, University of British Columbia, Vancouver, BC

The positions provided in the Point/Counterpoint series are presented as general information and do not necessarily reflect the personal opinions of the authors.

This article has been peer reviewed.

Competing interests: None declared.

\section{References}

1. Hodis HN. Assessing benefits and risks of hormone therapy in 2008: New evidence, especially with regard to the heart. Cleve Clin J Med 2008;75(S4):S3-12.

2. Jármy-di Bella Zl, Girão MJ, Di Bella V, et al. Hormonal influence on periurethral vessels in postmenopausal incontinent women using Doppler velocimetry analysis. Maturitas 2007;56:297-302.

3. Perrotta $C$, Aznar $M$, Mejia $R$, et al. Oestrogens for preventing recurrent urinary tract infection in postmenopausal women. Cochrane Database Syst Rev 2008;2:CD005131.

4. Griebling TL, Nygaard IE. The role of estrogen replacement therapy in the management of urinary incontinence and urinary tract infection in postmenopausal women. Endocrinol Metab Clin North Am 1997;26:347-60.

5. Nygaard IE, Kreder KJ. Pharmacologic therapy of lower urinary tract dysfunction. Clin Obstet Gynecol 2004;47:83-92.

6. Jackson S, Shepherd A, Brookes S, et al. The effect of oestrogen supplementation on post-menopausal urinary stress incontinence: a double-blind placebo-controlled trial. Br J Obstet Gynaecol 1999;106:711-8.

7. Hormone replacement therapy aggravates postmenopausal urinary incontinence. Prescrire Int 2006;15:137-8.

8. Antonicelli R, Olivieri F, Morichi V, et al. Prevention of cardiovascular events in early menopause: a possible role for hormone replacement therapy. Int I Cardiol 2008; 130:140-6.

9. Moehrer $B$, Hextall A, Jackson S. Oestrogens for urinary incontinence in women [review]. Cochrane Database Syst Rev 2003;2:CD001405.

10. Prentice RL, Chlebowski RT, Stefanick ML, et al. Conjugated equine estrogens and breast cancer risk in the Women's Health Initiative clinical trial and observational study. Am J Epidemiol 2008;167:1407-15.

11. Hendrix SL, Cochrane BB, Nygaard IE, et al. Effects of estrogen with and without progestin on urinary incontinence. JAMA 2005;293:935-48.

12. Tannen RL, Weiner MG, Xie D, et al. Perspectives on hormone replacement therapy: the Women's Health Initiative and new observational studies sampling the overall population. Fertil Steril 2008;90:258-64.

13. Theofrastous JP, Addison WA, Timmons MC. Voiding function following prolapse surgery. Impact of estrogen replacement. J Reprod Med 1996;41:881-4.
14. Shulman LP. Transdermal hormone therapy and bone health. Clin Interv Aging 2008; 3:51-4.

15. Ramnath N, Menezes RJ, Loewen $\mathrm{G}$, et al. Hormone replacement therapy as a risk factor for non-small cell lung cancer: results of a case-control study. Oncology 2007;73:305-10.

16. Steinauer JE, Waetien LE, Vttinghoff E, et al. Postmeopausal hermone therapy: Does it cause incontinence? Obstet Gynecol 2005;106:940-5.

17. Mancini F, Persico N, Genazzani AD, et al. Effects of hormone replacement therapy on plasma viscosity and Doppler variations in postmenopausal non-smokers and heavy smokers. Gynecol Endocrinol 2005;20:221-6.

18. Persico N, Mancini F. Artini PG, et al. Transdermal hormone replacement therapy and Doppler findings in normal and overweight postmenopausal patients. Gynecol Endocrinol 2004; 19:274-81.

19. Lukes A. Evolving issues in the clinical and managed care settings on the management of menopause following the Women's Health Initiative. J Manag Care Pharm 2008; 14(Suppl):7-13.

20. Grodstein F, Manson JE, Stampfer MJ, et al. Postmenopausal hormone therapy and stroke: role of time since menopause and age at initiation of hormone therapy. Arch Intern Med 2008;168:861-6.

21. Billeci AM, Paciaroni M, Caso V, et al. Hormone replacement therapy and stroke. Curr Vasc Pharmacol 2008;6:112-23.

22. Long $\mathrm{CY}$, Liu $\mathrm{CM}, \mathrm{Hsu} \mathrm{SC}$, et al. A randomized comparative study of the effects of oral and topical estrogen therapy on the lower urinary tract of hysterectomized postmenopausal women. Fertil Steril 2006;85:155-60.

23. Persico N, Mancini F, Artini PG, et al. Transdermal HRT and Doppler findings in normotensive and hypertensive postmenopausal patients. Ultrasound Obstet Gynecol 2005;26:546-51.

24. Canonico M. PluBureau G, Lowe GD, et al. Hormone replacement therapy and risk of venous thromboembolism in postmenopausal women: systematic review and metaanalysis. BMJ 2008;336:1227-31.

25. Juan YS, Mannikarottu A, Kogan BA, et al. The effect of low-dose estrogen therapy on ovarectomized female rabbit bladder. Urology 2008;71:1209-13.

26. Tantiwongse $K$, Fandel $T M$, Wang $G$, et al. The potential of hormones and selective oestrogen receptor modulators in preventing voiding dysfunction in rats. BJU Int 2008;102:242-6.

27. Stothers L. Complementary therapies in the management of lower urinary tract infection. In: Watson R, editor. Complementary and alternative therapies and the aging population. Salt Lake City: Academic Press; 2009.

28. Robinson D, Cardozo LD. The role of estrogens in female lower urinary tract dysfunction. Urology 2003;62(4 Suppl 1):45-51.

29. Qizo X, McConnell KR, Khalil RA. Sex steroids and vascular responses in hypertension and aging. Gend Med 2008;5(Suppl A):S46-64.

Correspondence: Dr. Lynn Stothers, UBC Bladder Care Centre, Department of Urology, University of British Columbia, Vancouver BC V6T 1Z3; lynns@interchange.ubc.ca 